\title{
The effects of score feedback and strategy of the other on cooperative behavior in a maximizing differences game
}

\author{
PHILIP S. GALLO, JR., ROBERTA IRWIN AND GERALD AVERY
}

SAN DIEGO STATE COLLEGE

Two experiments were conducted to determine the effects of information feedback on cooperative behavior in the Maximizing Differences Game. In Experiment 1, 120 male undergraduates received differential information concerning the cumulative point total that they and/or their partner had obtained. Information which permitted comparisons elicited the largest amount of competitive behavior. Forty-five male undergraduates took part in Experiment 2, which varied the strategy of a simulated "other." A delayed matching strategy was found to elicit greater cooperation than either fair games or highly cooperative random strategies.

The predominantly competitive behavior that has been observed in many studies of the Prisoner's Dilemma Game (Gallo \& McClintock, 1965) is difficult to interpret because of the confounding of motives inherent in the competitive choice. Because of this problem, McClintock \& Messick (1965) have suggested the use of the Maximizing Differences Game. It can be seen from Fig. 1 that the only motive for a competitive choice would be the player's desire to maximize the difference between his own gain and that of the other player. Two experiments were performed to determine the effects of informational feedback and strategy of the "other player" on behavior in the Maximizing Differences Game.

Method

One hundred sixty-five male students from introductory psychology courses at San Diego State College took part in the experiments. All Ss came to the laboratory in groups of two, and were seated in individu-

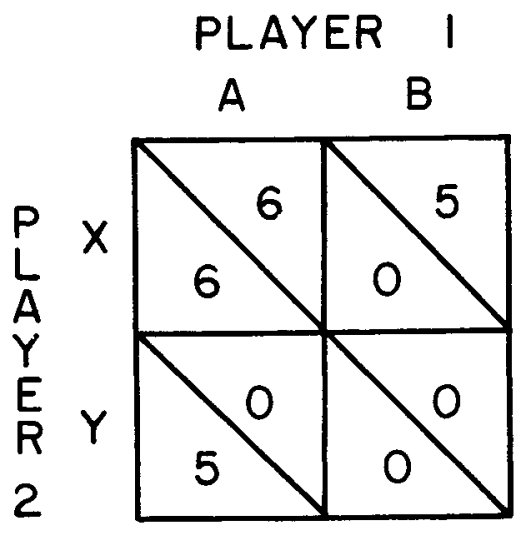

Fig. 1. A maximizing differences matrix. al cubicles. In front of each $\mathrm{S}$ was a game box, consisting of two buttons and four lights, with the matrix shown in Fig. 1 superimposed on it. The buttons for Player 1 were labeled $\mathrm{A}$ and $\mathrm{B}$, the buttons for Player 2 were labeled $X$ and $Y$. Complete instructions were given to the Ss via intercom. All combinations of choices and the payoffs associated with them were explained to the Ss. The instructions were kept as neutral as possible and it was stressed that the Ss should try and make as many points as possible.

All Ss played for 100 trials. The Ss were told that prizes would be given for certain point totals. A $\$ 1.98$ ball point pen was offered for 550 points, a 98 cent ball point pen for 450 points, and a 29 cent ball point pen for 350 points. The Ss were told that it was possible for them, one of them, or neither of them to win pens. Samples of the pens were on display boards in front of each S.

\section{Experiment 1}

One hundred twenty Ss were randomly assigned to four experimental groups in Experiment 1. The Ss in Group 1 were told, after each trial, the total number of points that both they, and the other player had accumulated. The Ss in Group II were told only their own accumulated point total, whereas Ss in Group III were told only the other player's cumulative point total. Group IV Ss were given no cumulative feedback. All Ss in Experiment 1 played a "fair game" with their opponents.

\section{Experiment 2}

Fourty-five Ss were randomly assigned to three experimental groups in Experiment 2. No cumulative feedback was given to any of these groups. All Ss in Experiment 2 played against prearranged strategies sent to them by the experimenter, although they believed they were playing against the other player. Groups V and VI played against a delayed matching (tit for tat) strategy in which they received the response that they had made on the previous trial. The $S s$ in Group $V$ received a cooperative response on Trial 1, the Ss in Group VI received a competitive response on Trial 1 . The Ss in Group VII played against non-contingent random strategies. Of the $15 \mathrm{Ss}$ in Group VII, four received 100 cooperative choices, four received 90, four received 85 , and three received 80 .

Results

Figure 2 shows the results of Groups I thru IV. Analysis of variance applied to the number of cooperative 


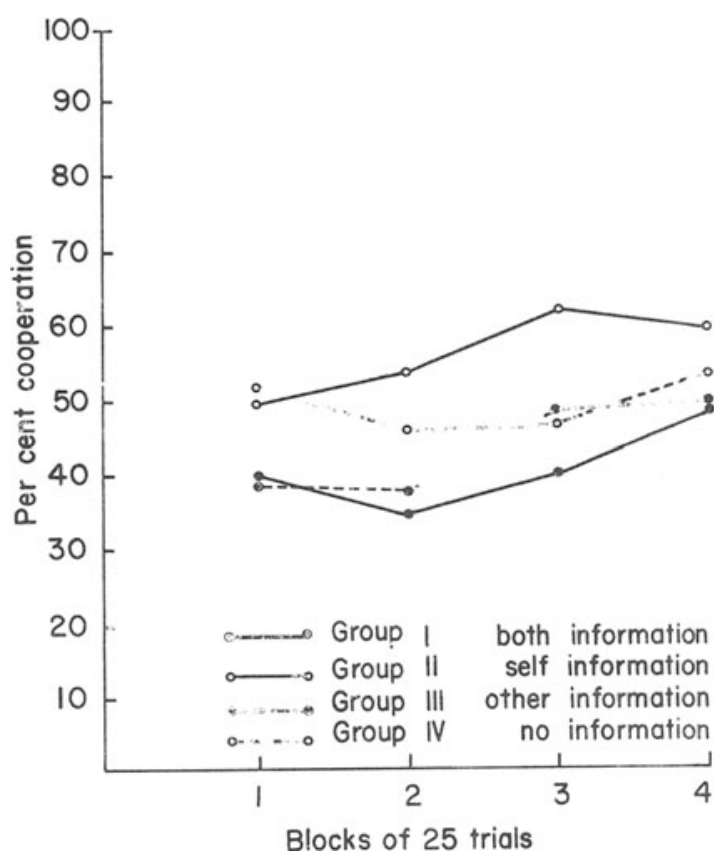

Fig. 2. Mean per cent of cooperative choices by blocks of twenty-five trials for Groups I through IV.

responses per dyad reveals no effect of presence or absence of cumulative feedback concerning the S'S own score. However, the presence or absence of feedback about the other person's score has an effect that reaches the .07 level of significance with greater competition when the other player's score is given to the Ss. A Duncan Multiple Range test was applied to the means of all four groups. This test indicated that Groups I and II are significantly different beyond the .05 level, in effect replicating the findings reported by McClintock \& Messick (1965).

Figure 3 shows the results of Groups IV thru VII. Group IV was included as a fair game control group. Analysis of variance and a Duncan Multiple Range test indicate that Groups V and VI (the delayed matching groups) are significantly more cooperative than Groups IV and VII at the .01 level of significance. Discussion

The overall results of the two experiments indicate that the obtained level of cooperation is somewhat higher than that usually encountered with Prisoner's Dilemma Matrices. On the other hand, the level of cooperation is much lower than one might expect given the values in the payoff matrix and the fact that the Ss could win reasonably attractive prizes for cooperating. Apparently, the motive to do better than the other player is a very strong one in this situation. Giving the Ss the opportunity to compare their performance with that

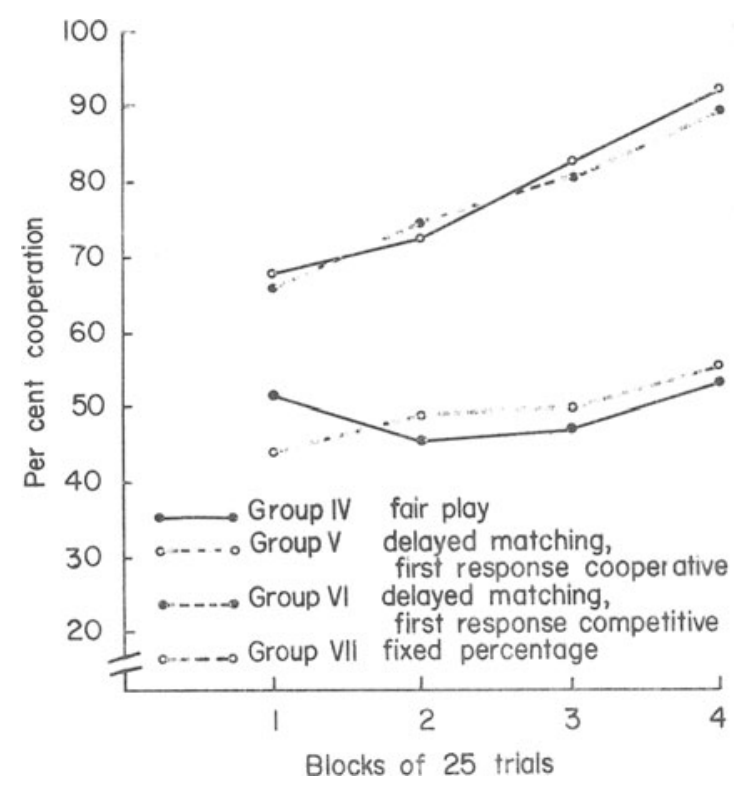

Fig. 3. Mean per cent of cooperative choices by blocks of twentyfive trials for Groups IV through VII.

of the other player seems to strengthen this motive.

The results of Experiment 2 indicate that greatly increased cooperation can be obtained when a delayed matching strategy is employed against the Ss. The crucial variable in eliciting cooperation from the Ss is not the number of cooperative responses that the $S$ received from the "other player"' but the way in which those responses are contingent upon his own behavior. In the delayed matching strategy, the $\mathrm{S}$ is always rewarded, one trial later, for a cooperative response, and punished, one trial later, for a competitive one. Of perhaps greater importance, after trial 1 , the $\mathrm{S}$ can never be "betrayed" by his "opponent." It will always be the real $\mathrm{S}$ who makes the first competitive response. Apparently, Ss are better able to forgive their own transgressions than those of their partner.

\section{References}

Gallo, P. S., Jr., \& McClintock, C, G. Cooperative and competitive behavior in mixed motive games. J. conflict Resolut, 1965, 9, 68-78.

McClintock, C. G., \& Messick, D. M. Strategic and motivational aspects of social interaction. A research grant proposal submitted to the National Science Foundation, 1965.

\section{Note}

1. This research was supported by the United States Air Force through the Air Force Office of Scientific Research of the Air Research and Development Command, under Contract Number AF 49(638)-794. 